\title{
LIGHT SCATTERING IN RESEARCH AND QUALITY CONTROL OF DEUTERIUM DEPLETED WATER FOR PHARMACEUTICAL APPLICATION
}

\section{A. M. KOLDINA*, E. V. USPENSKAYA, A. A. BORODIN, T. V. PLETENEVA, A. V. SYROESHKIN}

Department of Pharmaceutical and Toxicological Chemistry, Peoples Friendship University of Russia (RUDN University), 6 Miklukho-Maklaya St, Moscow, 117198, Russian Federation

Email: shadowmiss@mail.ru

Received: 24 Jun 2019, Revised and Accepted: 06 Aug 2019

\begin{abstract}
Objective: Development of a methodology for measuring the deuterium content in water for pharmaceutical purposes by laser light scattering based on ideas about the cluster structure of water.

Methods: Samples of industrially manufactured drinking water from different manufacturers with varying deuterium content from $10 \mathrm{ppm}$ to 115 $\mathrm{ppm}$. For the titration of laboratory samples of deuterium depleted water in increments of $5 \mathrm{ppm}$ the following reagents were used: Water, deuterium-depleted $\left(\leq 1 \mathrm{ppm}\left(\mathrm{D}_{2} \mathrm{O}\right.\right.$, Aldrich, USA); Deuterium oxide/Heavy water/Water- $\mathrm{d}_{2}$ ( 99.9 atom \% D, Aldrich, USA); water Milli-Q (specific resistance $18.2 \mu \mathrm{S} \cdot \mathrm{sm}$ at $25^{\circ} \mathrm{C}, \mathrm{TOC} \leq 5 \mathrm{ppb}$, Merck Millipore). The determination of deuterium content in samples of industrially manufactured water and water obtained in a laboratory manner was carried out by the method of low-angle laser light scattering (LALLS) at the Mastersizer (Malvern Instruments) analyzer and using a working measuring tool-laser dispersion meter/MDL («Cluster-1», Russia/Ukraine). The statistical methods-packages OriginProß9.
\end{abstract}

Results: It was found that the content of isotopologies in water leads to physicochemical water's properties changes and morphology changes of giant heterogeneous clusters (GHC). The results of low-angle laser light scattering (LALLS) in the water samples under investigation showed the dependence of the water GHC "dispersibility" expressed in the differentiation of curves of the volume size distribution ("size spectra"), the volume concentration, w\%, the laser obscuration values ( $\mathrm{I}-\mathrm{I}$ o) as the function of the water isotopic composition variations. The laser diffraction method results correlate with two-dimensional (2D) multi-descriptor mathematical analysis.

Conclusion: When identifying deuterium depleted water, it should be considered not only the indicators that determine its pharmacopoeial quality, but also the $\mathrm{D} / \mathrm{H}$ ratio, because even small changes in the natural isotopic composition of water lead to significant biological effects. Our proposed approach using laser diffraction in combination with mathematical apparatus of (2D) multi-descriptor laser scattering analysis makes possible the exact calculation of individual signs of deuterium depleted water as the pharmaceutical object of study.

Keywords: Deuterium depleted water, Isotope control, D/H ratio in water, Mathematical descriptors, LALLS method

(C) 2019 The Authors. Published by Innovare Academic Sciences Pvt Ltd. This is an open access article under the CC BY license (http://creativecommons.org/licenses/by/4.0/) DOI: http://dx.doi.org/10.22159/ijap.2019v11i5.34672

\section{INTRODUCTION}

Water quality control for pharmaceutical applications, according to the Pharmacopoeia requirements, includes routine tests of impurity content: nitrates, aluminum, heavy metals, control of bacterial endotoxins, number of viable aerobic microorganisms (Total Viable Aerobic Count), total organic carbon (total Organic Carbon in Water for Pharmaceutical Use) and specific electrical conductivity (not exceeding $4.3 \mu \mathrm{S} \cdot \mathrm{sm}^{-1}$ ) at $20^{\circ} \mathrm{C}$ [1]. Potable Water is not covered by a pharmacopoeial monograph but must comply with the regulations on water intended for human consumption of a quality equivalent to that defined in Council Directive 98/83/EC or laid down by the competent authority [2]. However, the requirements for the isotopic composition of water currently remain beyond the scope of the pharmaceutical analysis. Differences in physical properties of water ${ }_{1}^{1} \mathrm{H}_{2} \mathrm{O}$ and ${ }_{1}^{2} \mathrm{H}_{2} \mathrm{O}$ cause abnormally high natural variations of the isotopic composition: ${ }^{1} \mathrm{H}_{2}{ }^{16} \mathrm{O},{ }^{1} \mathrm{H}_{2}{ }^{17} \mathrm{O},{ }^{1} \mathrm{H}_{2}{ }^{18} \mathrm{O},{ }^{1} \mathrm{HD}^{16} \mathrm{O},{ }^{1} \mathrm{HD}^{17} \mathrm{O},{ }^{1} \mathrm{HD}^{18} \mathrm{O}$, $\mathrm{D}_{2}{ }^{16} \mathrm{O}, \mathrm{D}_{2}{ }^{17} \mathrm{O}, \mathrm{D}_{2}{ }^{18} \mathrm{O}[3,4]$. The concentration of deuterium ${ }^{2} \mathrm{H}(\mathrm{D})$ in natural water varies within the limits recorded in the standards of the isotopic composition of the hydrosphere SMOW-V, SLAP and GISP [5-7]. According to the SMOW-V standard, the content of stable isotopes in natural water is $\mathrm{D} / \mathrm{H}_{\text {smow }}=(155.76 \pm 0.05) \cdot 10^{-6}$. Therefore, water with a deuterium content below $155 \mathrm{ppm}$ can be defined as deuterium depleted water (ddw). The modern equipment makes it possible to produce deuterium depleted water with deuterium content in the range from 140 to $1 \mathrm{ppm}$, for example, by rectification of water under vacuum using a heat pump [8]. At the same time, the physical and chemical properties of the samples of such water are not considered, and the subsequent induction biological effects are not recorded. It exacerbates the problem of objective ddw quality control in accordance with the basic principles of the pharmaceutical analysis, therefore, it requires a full description of the physical and chemical properties of ddw. The latter condition is necessary not only for the standardization and development of routine ddw control procedures but also for understanding the mechanisms of its biological action. Deuterium in human plasma is redundant with concentrations reaching $12-14$ $\mathrm{mmol} / \mathrm{l}$ in comparison with calcium $(2.24-2.74 \mathrm{mmol} / \mathrm{l})$, potassium (5.0-5.1 mmol/l), and glucose (3.3-6.1 mmol/l) circulating concentrations. Concentration of deuterium in the body water correlates well with the deuterium level in the environment [9].

Since the discovery of heavy water in 1932, the effects of high and low concentrations of $\mathrm{D}_{2} \mathrm{O}$ on its biological objects have been studied. Replacing conventional hydrogen with heavy hydrogen leads to a decrease in the rate of chemical reactions (3 to 10 times), to a slowdown in many chemical reactions that determine complex biological processes in cells, tissues and the entire body [10-13].

The results of the research of using deuterium-depleted water that naturally occurring deuterium is essential for maintaining the normal cell growth rate study published in 1993 in the European Biochemical Societies journal, gave a new impetus to the development of scientific and practical interest in the biological effects of ddw [14]. It was shown [15] that long-term use of deuterium depleted water before irradiation (for $14 \mathrm{~d}$ ) led to an increase in the sensitivity of the chromosomal apparatus of mice to $\gamma$-irradiation against the background of increased mitotic activity of cells. The numerous results reveal that the growth of different animal cell lines in tissue culture is inhibited in deuterium-depleted water. This striking observation suggests that the natural abundance of $\mathrm{D}$ is essential to trigger and maintain the normal growth rate of the cell. In the in vivo experiments 
the longer survival and the fact that in 59\% of the tumorous mice the tumor disappeared because of the treatment with deuterium depleted water also suggest that the presence of $\mathrm{D}$ in a certain concentration is necessary for normal cell [16-25]

In several publications, ddw is presented as a component for the preparation of combined pharmaceutical compositions, as well as a solvent for increasing the solubilization characteristics of API [26-30].

Drinking water with a low content of deuterium is widespread both in veterinary practice and for daily human consumption. Deuterium depleted water with the ratio of $\mathrm{D} / \mathrm{H}=25 \pm 5 \mathrm{ppm}$ (Vetera-DDW-25 A. U. V., 13/99 FVM) induced complete or partial tumor regression in dogs and cats with spontaneous malignancies, it was registered as anticancer for veterinary use in 1999 [31]. The hypodermic preparation of the registered veterinary drug was successfully tested in clinical investigations.

Thus, there is every reason to believe that ddw is on the way from its consumption as drinking water to obtaining the status of "water for pharmaceutical purposes".

The existing methods of immediate off-line and on-line control of the isotopic composition of water in a wide range of concentrations densimetry, mass spectrometry, gravimetry, laser absorption spectroscopy, NMR, IR spectrometry are characterized by a significant error in the standard approach to the isotopic analysis of heavy water [32]. The proposed method of static low-angle laser light scattering with our technique of mathematical modeling of physical processes of agglomeration and formation of the cluster structure of water based on the calculation of physical and chemical descriptors is devoid of these shortcomings. Work [33] experimentally showed the influence of the isotopic composition of water samples with different $\mathrm{D} / \mathrm{H}$ ratios on self-organization of water clusters

The isotopic analysis of drinking water is complicated by the influence of salt composition, taking into account the need for drinking water conditioning as a result of rectification and ion exchange [34].

Thus, this article refers to water systems with different variable ratios and macroscopic properties of $\mathrm{D}_{2} \mathrm{O}$ and $\mathrm{H}_{2} \mathrm{O}$. Our work is aimed at studying the patterns of light scattering in samples of drinking and laboratory water with low deuterium content.

Thus, the aim of the present study was to develop a method for measuring the deuterium content in water for pharmaceutical purposes and further implement on-line control of its industrial production using laser light scattering based on ideas about the cluster structure of water.

\section{MATERIALS AND METHODS}

\section{Solutions under research}

Samples of industrially manufactured drinking water from different manufacturers with varying deuterium content from $10 \mathrm{ppm}$ to 115 ppm were investigated in the work: DDWater ("Super Light Water", Argentina, 115 ppm), DDW ("DDWater Bioengineering Co., Ltd.", Shanghai, China, 50 ppm), Helkare ("Henan Infinity Bioengineering Technology Co., Ltd.”, Hebi, China (mainland), 70 ppm), DDW (Swiss AG, 50 ppm), Himali (Daudoug, 60 ppm), DDW Langvey (LLC MTK Iceberg, Moscow, Russia, 50 ppm), DDW VIVIDI (JSC "Almaz", Kotovsk, Russia, 10 ppm).

High-resistance waters with the $[\mathrm{D} / \mathrm{H}]$ ratios of $45,50,55,60,70,75$, $80,85,90,95,100,105,115,120,125,130,140,145,150$ (ppm) were investigated. For the titration of laboratory samples of deuterium depleted water in increments of $5 \mathrm{ppm}$ the following reagents were used: Water, deuterium-depleted $\leqslant 1$ ppm (D ${ }_{2} \mathrm{O}$, Aldrich, USA); Deuterium oxide/Heavy water/Water-d $\mathrm{d}_{2}$ (99.9 atom $\% \mathrm{D}$, Aldrich, USA; water Mili-Q (specific resistance $18.2 \mu \mathrm{S}$ 'sm at 25 ${ }^{\circ} \mathrm{C}, \mathrm{TOC} \leq 5 \mathrm{ppb}$, Merck Millipore).
For conditioning of drinking water in terms of content of $\mathrm{Cl}^{-}$, $\mathrm{HCO}_{3}$ and $\mathrm{Na}^{+}$ions to correct the hydrogen index $(\mathrm{pH})$ of water, increase alkalinity and improve the taste of water, chemically pure substances were used as mineral additives. Aqueous solutions at $\mathrm{NaCl}$ and $\mathrm{NaHCO}_{3}$ ionic strengths $(\mathrm{pH}=7.0)$ of $1.2 ; 2.9 ; 4.6 ; 6.3 ; 8.0$; $11.5 \mathrm{mmol}$ with $[\mathrm{D} / \mathrm{H}]$ ratios (ppm) of $45,50,55,60,70,75,80,85$, $90,95,100,105,115,120,125,130,140,145,150$.

The pharmaceutical substance of sodium chloride $\mathrm{NaCl}$ and $\mathrm{NaHCO}_{3}$ (manufactured by Sigma, Aldrich, USA).

\section{Methods of differentiation of samples for research}

The solutions were filtered through a submicron inert membrane filter (Millex-GV Filter with a $0.22 \mu \mathrm{m}$ pore size hydrophilic PVDF membrane, Merck Millipore, UK).

\section{Laser diffraction method}

The determination of deuterium content in water samples obtained in industrial and laboratory manners was performed by static low-angle laser light scattering (LALLS) using the Master Sizer 2000 instrument, Zeta Sizer Nano ZS instrument (MALVERN Instruments, UK) and "Cluster-1"/MDL-1, laser meter of dispersion (manufactured by the Institute of Colloid Chemistry and Chemistry of Water, Ukraine and RUDN University, Russia) [35]. Laser scattering occurs on optical in homogeneities of the medium that appear when the refractive index changes [36]. To characterize the "dispersibility" of the samples, the grain-size distributions by volume and number fractions ("size spectra"), and the integral characteristics of "dispersibility" are subject to analysis: laser light scattering/laser obscuration value $(1-\mathrm{T})$, volume concentration (\%), specific surface area (sm3/g).

\section{D laser light scattering method}

To study the kinetics of "flickering" of giant heterogeneous water clusters (GHC), we used our method of 2D laser light scattering [37]. The main stages of the algorithm for calculating interference patterns: image segmentation, representation, description and image analysis for identification purposes [38]. To describe the local vicinities of the IR characteristic points, special descriptors-analogs of topological indexes, which are characterized by invariance at different geometrical and photometric transformations of the received image, are constructed: $S_{1} \div \mathrm{SD}_{3}, \mathrm{R}_{1} \div \mathrm{R}_{3}, \mathrm{R}$, where $\left(\mathrm{SD}_{1} \div\right.$ $\left.\mathrm{SD}_{3}\right)$ is the standard deviation from the mean; $\mathrm{R}_{\mathrm{i}}=\frac{\mathrm{d}_{\mathrm{i}}}{S D_{\mathrm{i}}}$ is signal-to-noise ratio (Signal/Noise, SNR) [39].

\section{Statistics}

The findings were processed by the statistical methods using software packages of Origin Pro 9.1. Each value on the fig. represents "mean $\pm S D ",{ }^{*} \mathrm{P}<0.05$.

\section{RESULTS}

\section{The influence of isotopy on the physicochemical water's properties}

The substitution of the hydrogen atom with deuterium leads to the fact that many physical, chemical and biological properties of $\mathrm{H}_{2} \mathrm{O}$ and $\mathrm{D}_{2} \mathrm{O}$ differ from each other. Compared with $\mathrm{H}_{2} \mathrm{O}^{16}$, the heavy water is characterized by higher values of density, boiling point, and melting point. The heat capacity of the heavy water at $20^{\circ} \mathrm{C}$ is $10 \%$ higher than that of the "light" one, the mobility of $\mathrm{D}^{+}$and OD-ions is almost $50 \%$ lower than that of $\mathrm{H}^{+}$and $\mathrm{OH}$-ions. Earlier, we published the results of a study of the properties of water with different contents of heavy isotopes of hydrogen by NMR spin echo, quasi-elastic scattering of slow neutron QSSN $(13,289 \mathrm{MeV})$, viscometry, and others $[40,41]$. The experimental data provide direct evidence that the density, surface tension, and water viscosity anomalies caused by variable deuterium concentration lead to the formation of clusters (density inhomogeneities) of water of different sizes, hence the realization of the isotope effect through the cluster organization of the associated liquid (fig. 1) [42]. 


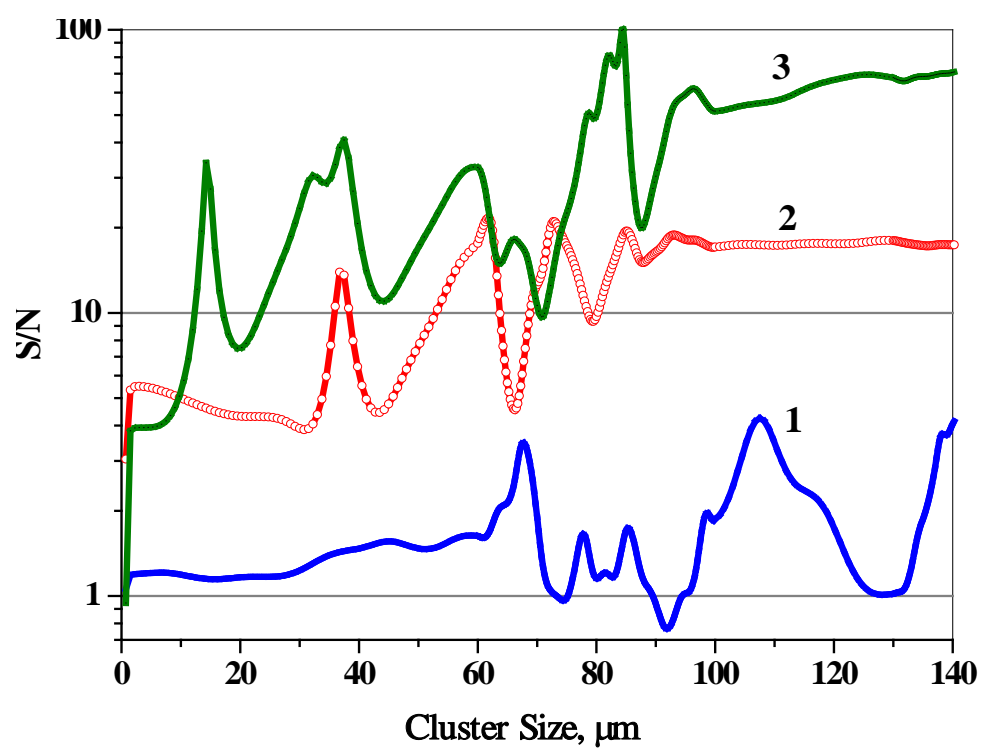

Fig. 1: Signal-to-noise ratio (SNR) when registering the size of water clusters by LALLS-method in water samples with the different content of heavy isotope of ${ }_{1}^{2} \mathrm{H}(\mathrm{D}): 1-140 \mathrm{ppm} ; 2-99.9 \% \mathrm{D}_{2} 0 ; 3-5 \mathrm{ppm}$ (deuterium depleted water); $\mathrm{n}=15 ; * \mathrm{P}<0.05, \mathrm{SNR}=\frac{\bar{V}}{S D}, \bar{V}$-average volume fraction (\%) of water clusters, SD-standard deviation

The graph shows a downward trend in the level of "noise" in the water in case of the replacement of protium by deuterium. Consequently, the $\mathrm{D} / \mathrm{H}$ ratio can act as the "control" parameter of water GHC size distribution.

The influence of the water isotopologies content on the morphology of water GHC

We used the method of low-angle light scattering to study the structure of deuterium-stabilized water giant heterogeneous clusters (GHC) formed in solutions. The feature of the problem to solve is the fact that in the study of aqueous solutions with different $\mathrm{D} / \mathrm{H}$ ratios, there is no possibility of analyzing them using well-known analytical methods. Using the physical principle of electromagnetic wave scattering on density inhomogeneities deuterium-stabilized water giant heterogeneous clusters, the angular distribution of the intensity of scattered light was measured as the laser beam was passing through a cell consecutively filled with laboratory samples of water with different D/H ratios (fig. 2).

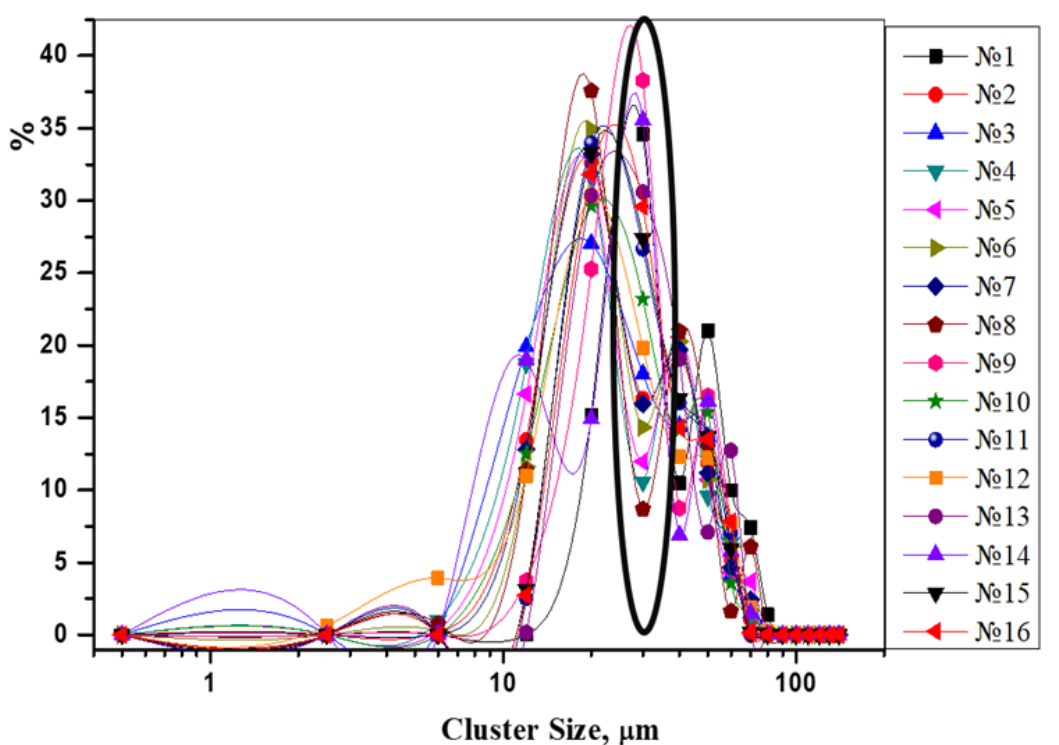

Fig. 2: The grain-size distributions by volume fractions ("size spectra") in laboratory samples of deuterium depleted water with different D/H ratios: № 1-10 ppm; № 2-20 ppm; № 3-30 ppm; № 4-40 ppm; № 5-45 ppm; № 6-50 ppm; № 7-55 ppm; № 8-60 ppm; № 9-70 ppm; № 10-80 ppm; № 11-90 ppm; № 12-100 ppm; № 13-110 ppm; № 14-120 ppm; № 15-130 ppm; № 16-140 ppm; n>5, *P<0.05

The grain-size distribution curves show the area of differentiation of all laboratory samples of deuterium depleted water at water GHC diameter $\mathrm{d}=30 \mu \mathrm{m}$. This difference allowed us to determine the characteristic areas occupied by deuterium depleted water samples when measuring calibration diagrams (fig. 3). 


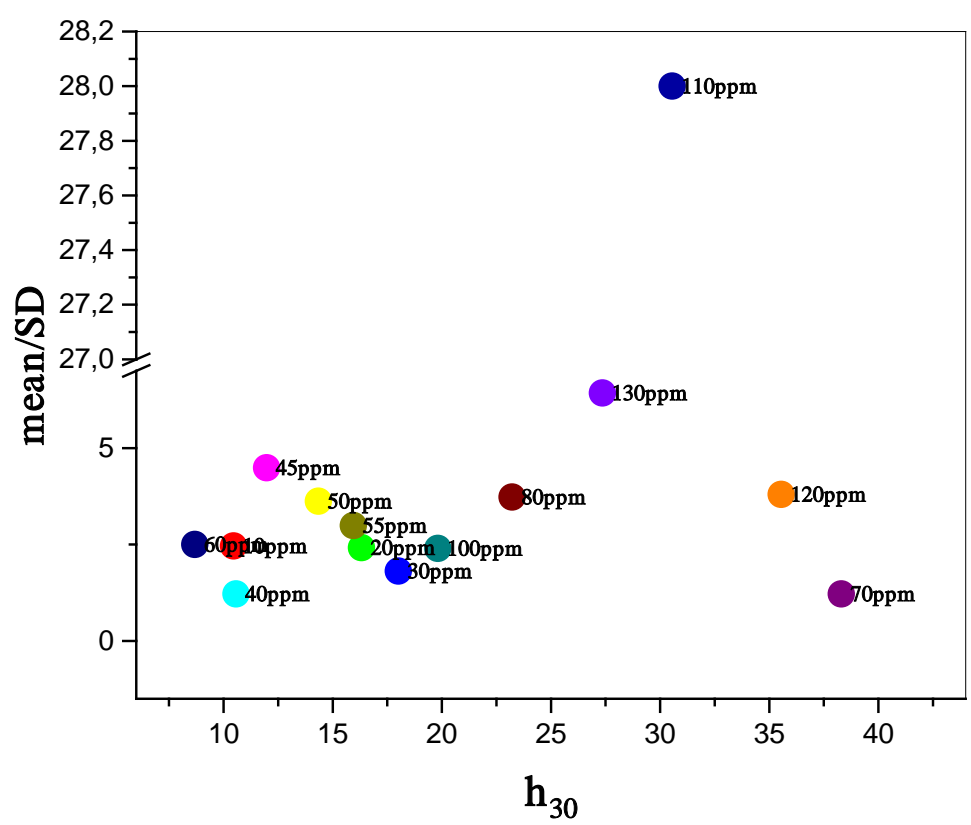

A

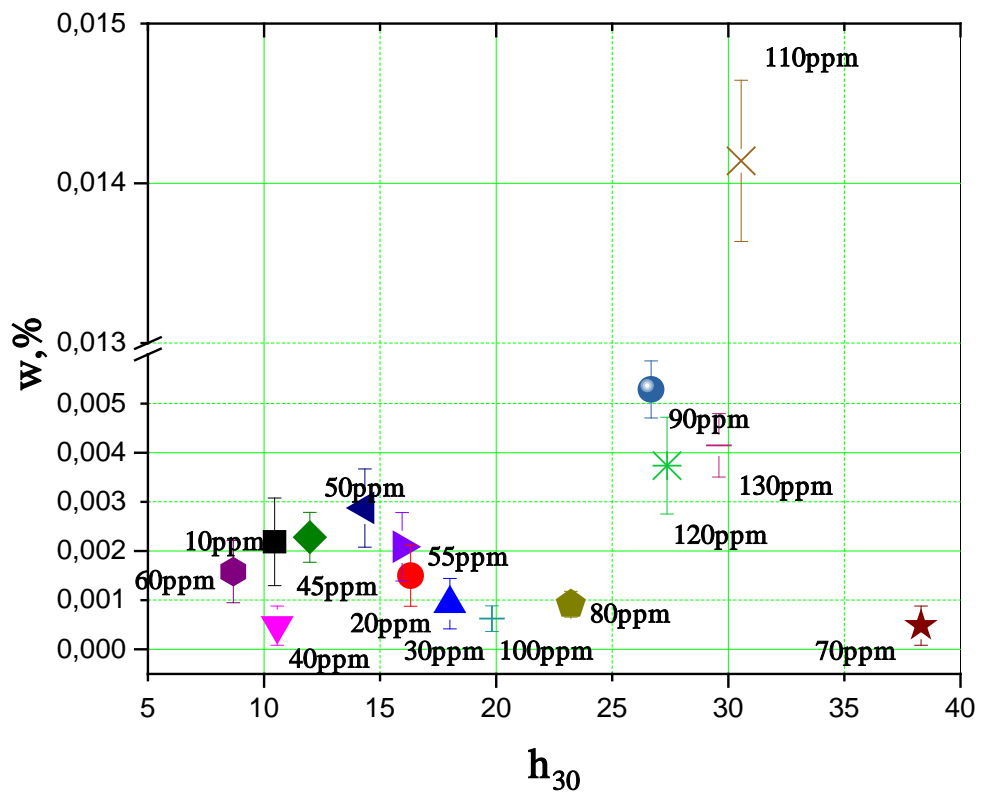

B

Fig. 3: The one-to-one correspondence between the SNR (A), the volume concentration, $w \%$ (B) and maxima of the $30 \mu \mathrm{m}$ water GHC size group; $n=5, * P<0.05$

\section{Measurement the content deuterium in drinking water based on mathematical models of diffraction method}

The technique is based on the calculations of the interference pattern formed by light beams after laser light scattering in the test sample on the acoustic wave (fig. 4).

\section{Mathematical descriptors}

The interference patterns recorded on the diode matrix undergo changes in time due to the kinetics of the formation and decay of water GHC and they were subjected to the mathematical analysis using descriptors $d_{1}, d_{2}$ and $d_{3}$, which are characterized by low variability at various geometric and photometric transformations of the image obtained in time (table 1 ).

\section{D Laser light scattering mathematical model}

The dependencies of the analytical signal and the standard deviation of the results on the $\mathrm{D} / \mathrm{H}$ ratio in the studied water samples were investigated. The results of the correlation method are presented in the form of two-dimensional (2D) diagrams of multi-descriptor analysis [43] (similar to the "fingerprint" in molecular biology) and make it possible to visually illustrate the topology of $2 \mathrm{D}$ laser scattering for a series of images of deuterium depleted water obtained by laboratory dilution and in industrial manner (fig. 5). 


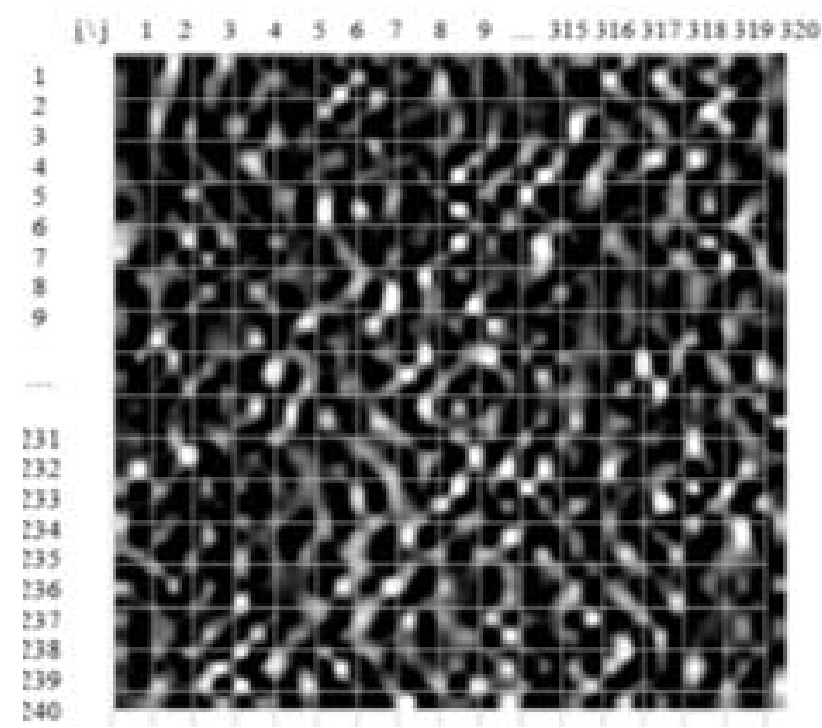

Fig. 4: Discrete representation of the interference pattern

Table 1: Mathematical representation of descriptors

\begin{tabular}{|c|c|c|}
\hline Descriptor & Mathematical representation & Description \\
\hline$d_{1}$ & $\begin{array}{l}\qquad \boldsymbol{d}_{\mathbf{1}}=\frac{\boldsymbol{i}_{\Delta S \boldsymbol{S}>S b}}{\boldsymbol{i}_{\boldsymbol{t}}} \cdot \mathbf{1 0 0} \% \\
\text { Where } \mathrm{i}_{\mathrm{t}} \text { is the total number of elements; } \Delta \mathrm{S}_{\mathrm{i}} \text { is the value of differences in the } \\
\text { signal level of the elements of two interference patterns; } \mathrm{S}_{\mathrm{b}} \text { is the threshold } \\
\text { level of the signal. }\end{array}$ & $\begin{array}{l}\text { - the number of different elements, regardless of } \\
\text { the degree of difference }\end{array}$ \\
\hline$d_{2}$ & $\begin{array}{l}\qquad \boldsymbol{d}_{\mathbf{2}}=\frac{\sum_{\Delta S i>S b} \Delta \boldsymbol{S}_{\boldsymbol{i}}}{\boldsymbol{i}_{\boldsymbol{t}} \cdot \overline{\boldsymbol{S}}} \cdot \mathbf{1 0 0} \% \\
\text { where } \sum_{\Delta S i>S b} \Delta S_{i} \text { is the average value of the signal level of all the elements of } \\
\text { the original interference pattern }\end{array}$ & $\begin{array}{l}\text { - the degree of difference for each discrete element } \\
\text { based on the original interference } \\
\text { pattern and the total intensity of the level of its } \\
\text { signal }\end{array}$ \\
\hline$d_{3}$ & $\begin{array}{l}\qquad \boldsymbol{d}_{\mathbf{3}}=\frac{\sum_{\Delta S i>S b} \Delta \boldsymbol{S}_{\boldsymbol{i}}}{\boldsymbol{i}_{\boldsymbol{t}} \cdot \Delta \boldsymbol{S}_{\max }} \cdot \mathbf{1 0 0 \%} \\
\text { where } \Delta S_{\max } \text { is the sum of max possible differences in terms of the signal } \\
\text { level of all the relevant elements of the interference patterns of absolute black } \\
\text { and absolute white }\end{array}$ & $\begin{array}{l}\text { - the max value of possible differences between the } \\
\text { interference patterns of absolute black and } \\
\text { absolute white }\end{array}$ \\
\hline
\end{tabular}
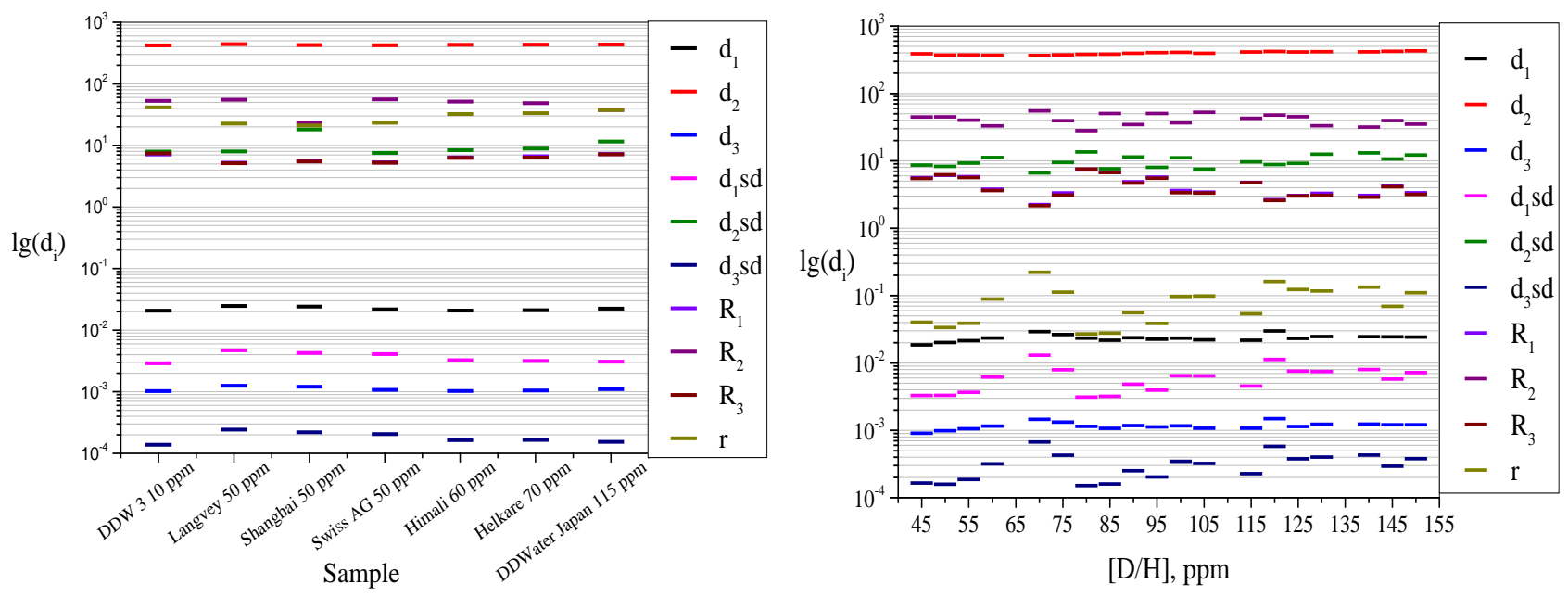

Fig. 5: Two-dimensional (2D) diagrams ("fingerprint") of the industrial water samples for ten descriptors for each sample (A) and the laboratory samples with different ratio $[D / H](B) ; n \geq 100, * P<0.05$

The comparison of different $\mathrm{D}_{2} \mathrm{O}$ and $\mathrm{H}_{2} \mathrm{O}$ dilutions both in laboratory dilutions and in samples of drinking water for pharmaceutical application shows that the multi-descriptor set is individual for each sample of dilution in a given interval. Therefore, comparing the value of each descriptor of an unknown dilution with the values of the corresponding descriptors of each of the dilutions from the calibration interval from 45 to $155 \mathrm{ppm}$, it is possible to determine the exact deuterium content in the water. 
Since drinking water and water for pharmaceutical recognition are subject to mandatory conditioning procedure for correcting the acidity $(\mathrm{pH})$ of water and enriching it with salts, we found it interesting to measure the calibration diagrams of deuterium depleted water samples saturated with sodium salts (fig. 6). From the literature, the effect of concentration and ionic strength of electrolyte solutions of the water GHC structure is well known [44].

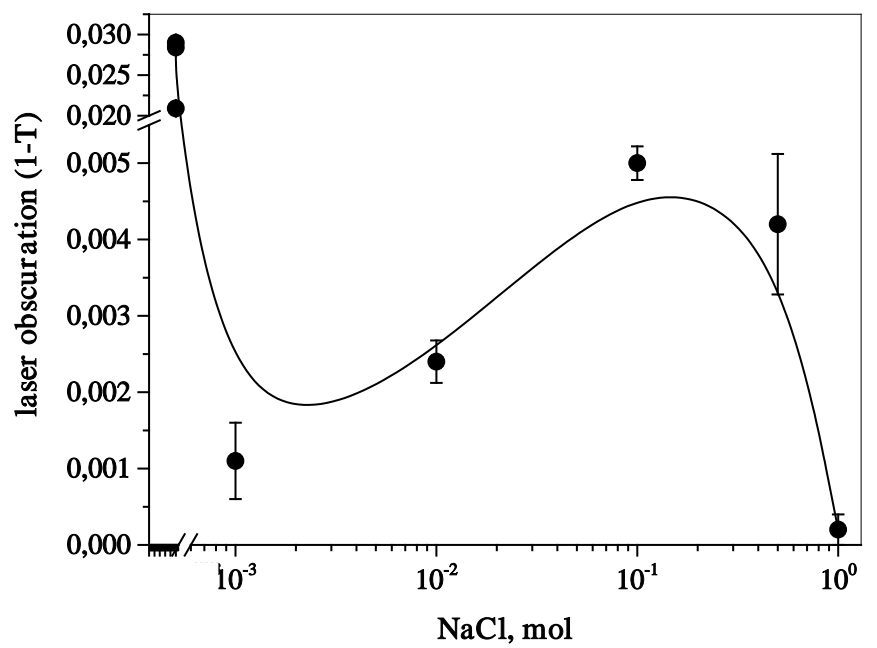

A

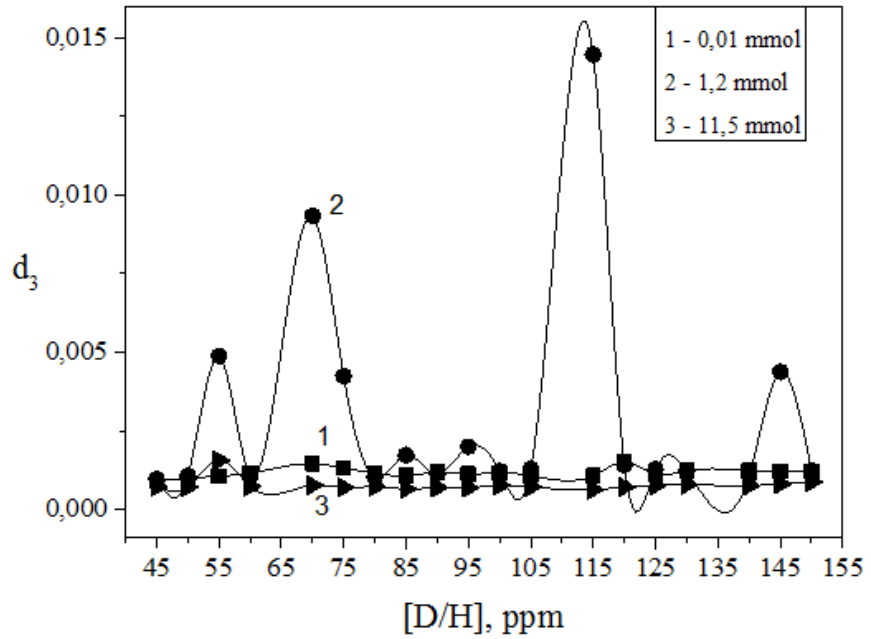

B

Fig. 6: The influence of concentration (ionic strength) of electrolyte $\mathrm{NaCl}$ solutions on the water GHC structure and the laser obscuration values (A); $n=15$, ${ }^{*}<<0.05$, Diagram of sd3 variability dependence on the value of $\mathrm{d} 3 \mathrm{descriptor}$ for the laboratory samples with different ratio $[\mathrm{D} / \mathrm{H}]$ and concentration (ionic strength) of electrolyte $\mathrm{NaCl}+\mathrm{NaHCO}_{3}$ solutions $(\mathrm{B}) ; \mathrm{n} \geq 100, * \mathrm{P}<0.05$

In $\mathrm{NaCl}$ solutions with ionic strength $\mathrm{I}=0.001 \mathrm{~mol}$, the light scattering ability of the solution drops sharply and becomes close to that of deionized water. A 100-time increase in the ionic strength of the solution contributes to the formation of water GHC, the light scattering ability of the solution increases dramatically.

\section{DISCUSSION}

It was found that the content of isotopologies in water leads to changes in the morphology of water giant heterogeneous clusters (GHC) and physicochemical water's properties, similarly with [45]. The results of low-angle laser light scattering in the water samples under investigation showed the dependence of the GHC "dispersibility" expressed in the differentiation of the laser obscuration values $(\mathrm{HI} 0)$, the volume concentration, \% and the curves of the volume size distribution function of the variations of the isotopic composition of water. The analysis of the signal-to-noise diagrams in the size group of $30 \mu \mathrm{m}$ revealed a differentiated location of the maxima in the histogram of the volume distribution.
The results of the LALLS-method correlate with the calculations made by us using a computer model based on the multi-descriptor analysis [46] and reliably describe the analytical characteristics of the samples for the comparative research using mathematical descriptors. It was shown [47] that the molecular topological indices are numerical invariants of a molecular graph and are useful to predict their physicochemical and biological properties. The study of laboratory dilutions of $\mathrm{D}_{2} \mathrm{O}$ and $\mathrm{H}_{2} \mathrm{O}$ and samples of industrially manufactured drinking water in the range of the $\mathrm{D} / \mathrm{H}$ ratio from 45 to $155 \mathrm{ppm}$ by the method of laser 2D light scattering [48] allowed the accurate calculation of the individual characteristics of deuterium depleted water due to the existence of "flickering" deuterium-stabilized water clusters.

\section{CONCLUSION}

There has been developed a method for measuring the deuterium content in water for pharmaceutical purposes and created a database that includes characteristics of industrially manufactured 
water samples and samples obtained in the laboratory. Laser diffraction in combination with mathematical apparatus of two-dimensional laser scattering analysis (2D) using variables of ten descriptors for each sample could to determine the $\mathrm{D} / \mathrm{H}$ ratio from 45 to $155 \mathrm{ppm}$ in water exactly and relate a test sample with a sample from the database. The results obtained reflect the distribution of density inhomogeneities in aqueous solutions (LALLS method) and mathematical description using descriptors. The developed method can be used during the water quality control in the production for pharmaceutical purposes, given that even small changes in the natural isotopic composition of water lead to significant biological effects.

\section{ACKNOWLEDGEMENT}

The publication has been prepared with the support of the "RUDN University Program 5-100".

\section{AUTHORS CONTRIBUTIONS}

All the authors have contributed equally

\section{CONFLICT OF INTERESTS}

The authors declare that there is no conflict of interest

\section{REFERENCES}

1. European Pharmacopoeia 7.0 V.1-2. Strasbourg: Council of Europe; 2010.

2. Guideline on the quality of water for pharmaceutical use. European Medicines Agency: London; United Kingdom; 2018. p. 10.

3. Xiao W, Wen X, Wang W, Xiao Q, Xu J, Cao C, et al. Spatial distribution and temporal variability of stable water isotopes in a large and shallow lake. Isot Environ Health Stud 2016;2:443-54.

4. Gabriel JB, James RE, Lesley AC, Erik, Thure E. Stable isotope ratios of tap water in the contiguous United States. Water Resour Res 2007;43:45-65.

5. Schoenemann SW, Schauer AJ, Steig EJ. Measurement of SLAP and GISP $\delta^{17} \mathrm{O}$ and proposed VSMOW-SLAP normalization for $\delta^{17} \mathrm{O}$ and ${ }^{17} \mathrm{O}$ (excess). Rapid Commun Mass Spectrom 2013;5:582-90.

6. Gehre M, Höfling R, Kowski P. Methodical studies for $\mathrm{d} / \mathrm{h}$-isotope analysis-a new technique for the direct coupling of sample preparation to an irms. Water Resour Res 1996; 4:335-40.

7. Barkan E, Luz B. High precision measurements of ${ }^{17} \mathrm{O} /{ }^{16} \mathrm{O}$ and ${ }^{18} \mathrm{O} /{ }^{16} \mathrm{O}$ ratios in $\mathrm{H}_{2} \mathrm{O}$. Rapid Commun Mass Spectrom 2005;24:3737-42

8. Mladin C, Popescu AL, Stefanescu I, Oubraham A. Deuterium depleted water-new studies about isotopic distillation obtaining process. Asian J Chem 2013;14:7976-8.

9. Rehakova R, Klimentova J, Cebova M, Barta A, Matuskova Z Labas $\mathrm{P}$, et al. Effect of deuterium-depleted water on selected cardiometabolic parameters in fructose-treated rats. Physiol Res 2016;S:401-S407.

10. Christopher MH, Pollegioni L, Ghisla S. pH and kinetic isotope effects in d-amino acid oxidase catalysis. Eur J Biochem 2001;21:5504-20.

11. Gorokhov VV, Knox PP, Korvatovsky BN, Paschenko VZ, Zakharova NI, Rubin AB. Effect of deuteration and cryosolvents on the energy transduction in primary processes of photosynthesis. Membr Cell Biol 1998;5:593-608.

12. Makhatadze GI, Clore GM, Gronenborn AM. Solvent isotope effect and protein stability. Nat Struct Biol 1995;10:852-5.

13. Mei M. Whittaker, David P Ballou, James W. Whittaker kinetic isotope effects as probes of the mechanism of galactose oxidase. Biochemistry 1998;37:8426-36.

14. Somlyai G, Jancsbb G, Jhklib G, Vass K, Barna B, Lakicsd V, et al. Naturally occurring deuterium is essential for the normal growth rate of cells. Eur Biochem Soc 1993;1:2-14.

15. Vorozhtsova SV, Abrosimova AN, Kulikova EI, Dorozhkina OV, Kovalenko MA, Kriuchkova DM, et al. Modification of the cytogenetic effects of irradiation by water with the reduced content of deuterium and heavy isotopes of oxygen. Radiats Biol Radioecol 2014;1:21-6.

16. Somlyai G, Laskay G, Berkenyi T. The biological effects of deuterium-depleted water, a possible new tool in cancer therapy. J Oncol 2001;30:91-4.

17. Somlyai G. The biological effect of deuterium-depleted water. A possible new tool in cancer therapy. Anticancer Res Intern J 2002;3:23-33.

18. Somlyai G, Molnar M, Laskay G, Szabo M, Berkenyi T, Guller I, et al. Biological significance of naturally occurring deuterium: the antitumor effect of deuterium depletion. Orv Hetil 2010;36:1455-60.

19. Gyongyi Z, Budan F, Szabo I, Ember I, Kiss I, Krempels K, et al. Deuterium depleted water effects on survival of lung cancer patients and expression of Kras, Bcl2, and Myc genes in mouse lung. Nutr Cancer 2013;2:240-6.

20. Stom DI, Ponomareva AK, Vyatchina OF. Deuterium depletion from tissue culture to human clinical studies. In: $2^{\text {nd }}$ International Congress on Deuterium Depletion 2006;4:20-1.

21. Torok G, Cski M, Pinte A. Influense of water with varying content of deuterium on red californian hybride (Eusenia fetida Andrei Bouche). Bull RAS 2000;52:167-9.

22. Thomson JF. Effects of different deuterium concentrations of the media on the bacterial growth and mutagenesis. Egeszsegtudomany/Health Sci 1960;44:331-8.

23. Tsukamoto H. Physiological effects of D2O in mammals. Deuterium isotope effects in chemistry and biology. Annals New York Acad Sci 2009;84:736-44.

24. Rehakova R, Klimentova J, Cebova M, Barta A, Matuskova Z, Labas $\mathrm{P}$, et al. Age-associated increase in lifespan of navie CD4 $\mathrm{T}$ cells contributes to $\mathrm{T}$-cell homeostasis but facilitates development of functional defects. Proc Natl Acad Sci USA 2009;43:18333-8.

25. Rehakova R, Klimentova J, Cebova M, Barta A, Matuskova Z Labas P, et al. Effect of deuterium-depleted water on selected cardiometabolic parameters in fructose-treated rats. Physiol Res 2016;S:401-S407.

26. Nelson D, William F. Trager the use of deuterium isotope effects to probe the active site properties, mechanism of cytochrome p450-catalyzed reactions, and mechanisms of metabolically dependent toxicity sidney. Drug Metab Disposition 2003;12:1481-98.

27. Ding Z, Hou Y, Wang S, Sun T, Ma M, Guan H, et al. Synthesis of deuterium-enriched and fluorine-substitutedplinabulin derivatives and evaluation of their antitumor activities. Mol Divers 2017;3:577-83.

28. Kaur S, Gupta M. Deuteration as a tool for optimization of metabolic stability and toxicity of drugs. Glob J Pharm Sci 2017;4:1-11.

29. Uspenskaya EV, Anfimova EV, Syroeshkin AV, Pleteneva TV. Kinetics of pharmaceutical substance solubility in water with different hydrogen isotopes content. Indian J Pharm Sci 2018;80:318-24.

30. Syroeshkin AV, Pleteneva TV, Uspenskaya EV, Levitskaya OV, Tribot-laspiere MA, Zlatsky IA, et al. Polarimetric research of pharmaceutical substances in aqueous solutions with different water isotopologues ratio. Int J Appl Pharm 2018;10:243-8.

31. Gyongyi Z, Somlyai G. Deuterium depletion can decrease the expression of C-myc Ha-ras and p53 gene in carcinogen-treated mice. In vivo 2000;3:437-9.

32. Voronina TV, Fedorchenko OA. Measuring the protium concentration in highly concentrated heavy water by IR spectrometry. Progress of criogenics and isotopes separation. Rm Valcea 2006;18:24-30.

33. Tachikawa M, Shiga M. Geometrical H/D isotope effect on hydrogen bonds in charged water clusters. Am Chem Soc 2005;34:1908-9.

34. Scott B, Penny K. A decision support system for rectification action planning in the sydney drinking water catchments. Eng Australia Causal Prod 2008;1:2261-72.

35. Syroeshkin AV, Popov PI, Grebennikova TV. Laser diffraction for standardization of heteroge-neous pharmaceutical preparations. J Pharm Biomed Anal 2005;37:927-30. 
36. Hung J, Barton J Dear, Carl A Karouta, Amjad A Chowdhury, P Douglas Godfrin, Jonathan A Bollinger, et al. Johnston protein-protein interactions of highly concentrated monoclonal antibody solutions via static light scattering and influence on the viscosity Jessica. J Phys Chem 2019:4:739-55.

37. Uspenskaya EV, Syroeshkin AV, Smirnov AN. The structure of water and laser rapid methods for determining authenticity. Farmatsiya 2007;5:21-3.

38. Dengsheng Z, Lu A. Guojun comparative study on shape retrieval using fourier descriptors with different shape signatures. J Visual Commun Image Rep 2003;1:41-60.

39. Syroeshkin AV, Stepanova NA, Popov PI. Prognostication of toxicity of a group of chemical compounds comprising anti-tuberculosis medicines by the quantitative structure-activity correlation method. Forensic Med Exam 2009;4:210-7.

40. Goncharuk VV, Lapshin VB, Burdeinaya TN, Pleteneva TV, Chernopyatko AS, Atamanenko ID, et al. Physicochemical properties and biological activity of the water depleted of heavy isotopes. J Water Chem Technol 2011;1:8-13.

41. Koszinowski K, Stephenson DS. Large solvent isotope effect associated with the hydrolysis of allylindium iodide. J Org Chem 2018;23:14314-22.
42. Yakhno T, Yakhno VA. Study of the structural organization of water and aqueous solutions by means of optical microscopy. Crystals 2019;1:52-8.

43. Suhane S, Nerkar AG, Modi K, Sawant SD. "2D and 3D-qsar analysis of amino (3-( (3, 5-difluoro-4-methyl-6-phenoxypyridine-2-yl) oxy) phenyl) methaniminium derivatives as factor xa inhibitor". Int J Pharm Pharm Sci 2019;2:104-11.

44. Abascal JLF, Bresme F. The influence of concentration and ionic strength on the cluster structure of highly charged electrolyte solutions. Mol Phys 1994;1:143-56.

45. PSDRD, Bn VH. Effect of water content in kneading method of solid dispersion technique for solubility enhancement. Int J Appl Pharm 2017;5:14-21.

46. Vigneresse JL, Truche L. Chemical descriptors for describing physico-chemical properties with applications to geosciences. Mol Model 2018;9:231-9.

47. Iqbal Z, Ishaq M, Aslam A. On eccentricity-based topological descriptors of water-soluble dendrimers. Zeitschrift fur Naturforschung C 2018;2:25-33.

48. Lessang R, Soeroso Y, Juand A, Kuswandan SO. A low-dose laser (diode laser) application reduces pocket periodontal depth and clinical attachment loss. Int J Appl Pharm 2018;9:121-4. 